\title{
Oxidative stress markers in patients with hereditary angioedema
}

\author{
Stefano R. Del Giacco ${ }^{1}$, Davide Firinu ${ }^{1}$, Paola Lucia Minciullo², Maria Pina Barca ${ }^{1}$, \\ Paolo Emilio Manconi ${ }^{1}$, Gennaro Tartarisco ${ }^{3}$, Mariateresa Cristani ${ }^{4}$, Antonella Saija ${ }^{4}$, \\ Sebastiano Gangemi ${ }^{2}$
}

1'Department of Medical Sciences "M. Aresu”, University of Cagliari, Cagliari, Italy
${ }^{2}$ School and Operative Unit of Allergy and Clinical Immunology, Department of Clinical
and Experimental Medicine, University of Messina, Messina, Italy
${ }^{3}$ National Research Council of Italy (CNR) - Institute of Applied Science and Intelligent
System (ISASI), Messina Unit, Messina, Italy
${ }^{4}$ Department of Drug Sciences and Health Products, University of Messina, Messina, Italy

Submitted: 2 October 2016

Accepted: 18 January 2017

Arch Med Sci 2019; 15, 1: 92-98

DOI: https://doi.org/10.5114/aoms.2017.66160

Copyright $\odot 2017$ Termedia \& Banach

\section{Abstract}

Introduction: Hereditary angioedema due to $\mathrm{C} 1-\mathrm{INH}$ deficiency (C1-INH-HAE) or with normal $\mathrm{C} 1-\mathrm{INH}$ is characterized by recurrent swellings due to uncontrolled production of vasoactive mediators, among which bradykinin (BK) is crucial. Through the binding and activation of the two human BK-receptors, kinins may have dual beneficial and deleterious effects in vascular and inflammation physiopathology by inducing oxidative stress. We aimed to assess the serum concentrations of advanced glycation end products (AGEs) and advanced oxidation protein products (AOPPs) in patients affected by HAE.

Material and methods: Blood samples were collected to measure the serum concentrations of AGEs and AOPPs by spectrofluorimetric and spectrophotometric methods in patients affected by C1-INH-HAE and FXII-HAE during the remission state.

Results: We showed that the circulating levels of AOPPs observed on control group $(0.94(0.36) \mathrm{nmol} / \mathrm{mg})$ were significantly lower than those observed on the C1-INH-HAE group (1.68 $(0.47) \mathrm{nmol} / \mathrm{mg} ; p=0.002)$ and FXII-HAE $(1.50(0.27) \mathrm{nmol} / \mathrm{mg} ; p=0.001)$. Moreover, the circulating levels of AGEs were significantly higher in C1-INH-HAE group (211.58 (151.05) AU/g; $p=$ 0.02 ) than the FXII group (141.48 (89.59) AU/g), thus demonstrating a state of heightened oxidative stress.

Conclusions: Our observations show additional underlying events involved in HAE and are of central importance for further investigations of differences in bradykinin receptors signaling among the two disease subgroups.

Key words: hereditary angioedema, C1-inhibitor, bradykinin, oxidative stress, kinin.

\section{Introduction}

Hereditary angioedema (HAE) encompasses a group of rare diseases characterized by recurrent subcutaneous or submucosal long-lasting swellings (24 to $96 \mathrm{~h}$ when untreated) that commonly involve the extremities, the face, the genitals, the bowel and the upper airways [1]. Potentially, the occurrence of events such as laryngeal attacks or, rarely, hypovolemic shock is life-threatening $[2,3]$. The most frequent disease

\author{
Corresponding author: \\ Dr. Davide Firinu \\ Department \\ of Medical Sciences \\ "M. Aresu" \\ Unit of Internal Medicine \\ Allergy and Clinical \\ Immunology \\ University of Cagliari \\ Azienda Ospedaliero \\ Universitaria \\ SS 554-Bivio Sestu \\ I-09042 Monserrato (CA), Italy \\ Phone: +39070 51096128 \\ Fax +39070 51096227 \\ E-mail: davide.firinu@unica.it
}


type is caused by quantitative or functional deficiency of the serine protease inhibitor C1-esterase inhibitor $(\mathrm{C} 1-\mathrm{INH})$ protein, due to mutations in the gene SERPING1 [1]. The resulting C1-INH-HAE is defined as type I or type II and it affects the complement, contact and fibrinolytic cascades, leading to uncontrolled production of vasoactive mediators, among which the release of bradykinin (BK) is crucial $[4,5]$. BK is also the major mediator in the HAE subtype defined by normal C1-INH function [6]. Mutations in the $F 12$ gene have been described in a large proportion of families affected by this subtype of HAE, named FXII-HAE $[7,8]$.

Oxidative stress is the result of an imbalance between endogenous production of free reactive oxygen species (ROS) and reduced effectiveness of antioxidant defense mechanisms. This imbalance can worsen inflammation and injury conditions by enhancing release of pro-inflammatory cytokines and altering enzymatic function [9]. Oxidative stress occurs in many inflammatory, neoplastic and immunologic diseases, including asthma, allergic rhinitis, obesity and leukemia [9-11].

Advanced oxidation protein products (AOPPs) and advanced glycation end products (AGEs) are a family of compounds generated in body fluids from oxidation of macromolecules, including proteins, used as markers of oxidative stress and inflammation in several diseases and their complications [11-15]. The AOPPs are protein derivatives, predominantly albumin, and its aggregates mainly formed by chlorinated oxidants. The AGEs, e.g., pentosidine and carboxymethyllysine, are formed via autoxidation of sugars as well as other glycation intermediates and via lipoperoxidation of polyunsaturated fatty acids.

Kinin vasoactive peptides participate in inflammatory processes through the binding and activation of two G-protein-coupled receptors (R): B1R, inducible by proinflammatory cytokines and oxidative stress via the transcriptional nuclear factor $\kappa B$ (NF$\kappa B$ ), and $B 2 R$, which is expressed constitutively and increases vascular permeability [16]. B1R is a potent activator of inducible nitric oxide and NADPH oxidase, which are associated with vascular inflammation, increased permeability, and endothelial dysfunction [17]. However, there are no data available data on oxidative stress in patients with HAE.

This study aimed to assess the serum concentrations of AGEs and AOPPs in patients affected by HAE due to C1-INH deficiency and HAE with normal $\mathrm{C} 1-\mathrm{INH}$.

\section{Material and methods}

\section{Study subjects, laboratory tests and HAE diagnosis}

We consecutively investigated patients from families with C1-INH-HAE and families diagnosed with FXII-HAE. Patients were recruited at the Unit of Internal Medicine, Allergy and Clinical Immunology (University of Cagliari, Italy). We studied 19 C1-INH-HAE patients, 15 FXII-HAE patients and 21 healthy controls. The blood samples were taken during the remission state, which was defined as asymptomatic for at least 15 days before sampling. Furthermore, sera were collected prior to the prescription of drugs such as tranexamic acid, attenuated androgens or long-term prophylaxis with $\mathrm{C} 1-\mathrm{INH}$.

Exclusion criteria at the moment of blood sampling were: the presence of concurrent diseases or conditions and the intake of drugs and dietary supplements known to interfere with oxidative stress marker levels.

The diagnosis of C1-INH-HAE and of FXII-HAE was established on the basis of complete clinical history and laboratory tests, according to published criteria [1]. In both groups, affected asymptomatic subjects were identified through familial screening.

Plasma levels of C1-INH antigen were assayed by radial immunodiffusion (NOR Partigen $\mathrm{C} 1-\mathrm{INH}$, Siemens Healthcare Diagnostics, Marburg, Germany), (4 antigen by nephelometry, and C1-INH activity in plasma using a chromogenic assay (Technochrom C1-Inhibitor, Technoclone, Vienna, Austria). Quantitative D-dimer assay was performed by a latex immunoassay (Hemosil D-dimer HS, Instrumentation Laboratory SpA, Italy).

Based on the clinical history, the patients were previously evaluated as appropriate on the basis of known causes of angioedema, including the sequence of SERPING 1 and $F 12$ genes [18-20]. C1-INH-HAE and HAE-FXII severity scores were calculated respectively according to Gomez-Traseira et al. and Bygum et al. [21, 22].

The study was carried out after approval by the local ethics committee (protocol NP/2013/3226), in accordance with the Principles of the Declaration of Helsinki and its amendments; written informed consent for the study was obtained from all the participants.

\section{Advanced glycation end products and advanced oxidation protein products}

The AGEs and AOPPs were measured by spectrofluorimetric and spectrophotometric methods, respectively, as previously described $[12,23]$.

For AGE determination, serum was diluted $1: 50$ with phosphate-buffered saline (PBS; $\mathrm{pH}$ 7.4), and fluorescence intensity was recorded at maximum emission $(\sim 40 \mathrm{~nm})$ upon excitation at $350 \mathrm{~nm}$ and expressed in arbitrary units (AU). The serum concentration of AGEs was normalized to the total protein amount determined by the Bradford assay and expressed in $\mathrm{AU}$ per gram of protein. 
For AOPP determination, $200 \mu \mathrm{l}$ of blood serum diluted $1: 5$ with PBS, $200 \mu$ l of chloramines T (0$100 \mathrm{~mol} / \mathrm{l})$ for calibration, or $200 \mu \mathrm{l}$ of PBS as blank were applied on a microtiter plate. Ten $\mu \mathrm{l}$ of $1.16 \mathrm{M} \mathrm{KI}$ and $20 \mu \mathrm{l}$ of acetic acid were added, and absorbance at $340 \mathrm{~nm}$ was measured immediately. The serum concentration of AOPPs was normalized to the total protein amount determined by the Bradford assay and expressed as chloramines $\mathrm{nmol} / \mathrm{mg}$ of protein.

Each sample was analyzed in triplicate for both AGE and AOPP determination.

\section{Statistical analysis}

Statistical analysis was performed using SPSS 22 for Windows. Data were analyzed using non-parametric methods. Statistical significance was assessed by the Kruskal-Wallis $\mathrm{H}$ test, which does not assume a normal distribution of measured variables. Results of concentrations of AOPP and AGE levels are expressed as median (interquartile range). Post hoc analysis based on the Dunn-Bon- ferroni approach was performed and statistical significance was achieved when $p<0.05$.

\section{Results}

The characteristics of the population investigated are summarized in Tables I-III.

The Kruskal-Wallis $\mathrm{H}$ test showed that there was a statistically significant difference in AOPP (nmol/mg) between the three different groups, $\chi^{2}(2)=26.574, p=0.001$, with a mean rank AOPP value of 39.63 for C1-INH-HAE, 32.47 for FXII-HAE and 14.29 for the control group. Post hoc analysis of AOPP levels (Figure 1) showed that the control group had a concentration of $0.94(0.36) \mathrm{nmol} /$ $\mathrm{mg}$, which was significantly lower than levels in the C1-INH-HAE group (1.68 (0.47) $\mathrm{nmol} / \mathrm{mg}$; $p=0.002)$ or FXII-HAE (1.50 (0.27) $\mathrm{nmol} / \mathrm{mg}$; $p=0.001)$. Also differences in AGE levels (AU/g) were statistically significant, $\chi^{2}(2)=9.18, p=$ 0.010 , with a mean rank AGE value of 35.37 for C1-INH-HAE, 18.60 for FXII-HAE and 28.05 for the

Table I. Clinical features of healthy subjects and patients affected by HAE

\begin{tabular}{|lccc|}
\hline Parameter & Healthy subjects $(n=21)$ & C1-INH-HAE $(n=19)$ & FXII-HAE $(n=15)$ \\
\hline Sex $($ M/F $)$ & $6 / 15$ & $7 / 12$ & $3 / 12$ \\
\hline Age, average [years] & 37.5 & 49 & 38 \\
\hline Range [years] & $18-54$ & $16-81$ & $10-66$ \\
\hline
\end{tabular}

Table II. Clinical and laboratory data of patients affected by FXII-HAE

\begin{tabular}{|c|c|c|c|c|c|c|c|c|c|}
\hline $\begin{array}{l}\text { FXII-HAE } \\
\text { Pt id }\end{array}$ & Gender & Age & $\mathrm{C} 4$ & $\begin{array}{l}\text { C1-INH } \\
\text { antigen }\end{array}$ & $\begin{array}{c}\text { C1-INH } \\
\text { function \% }\end{array}$ & Fibrinogen & $\begin{array}{c}\text { D-dimer } \\
\text { (basal) }\end{array}$ & $\begin{array}{c}\text { Symptoms } \\
(y / n)\end{array}$ & HAE-FXII score \\
\hline 1 & $\mathrm{~F}$ & 47 & 20 & 20.6 & 90 & & & Y & Severe \\
\hline 2 & $\mathrm{~F}$ & 44 & 28 & 27 & 93 & 323 & 215 & Y & Moderate \\
\hline 3 & $\mathrm{~F}$ & 58 & 16 & 26.8 & & & 330 & Y & Severe \\
\hline 4 & $\mathrm{~F}$ & 43 & 13 & 28.1 & 80 & 1080 & & $Y$ & Severe \\
\hline 5 & $\mathrm{~F}$ & 32 & 23 & 27.6 & & & 380 & $Y$ & Mild \\
\hline 6 & $\mathrm{~F}$ & 32 & 20 & 26.2 & 75 & 268 & 90 & $Y$ & Severe \\
\hline 7 & $M$ & 62 & & & & & & $\mathrm{~N}$ & Asymptomatic \\
\hline 8 & $\mathrm{~F}$ & 31 & 14 & 17.4 & 85 & 250 & 338 & Y & Moderate \\
\hline 9 & $M$ & 15 & 18 & 24.6 & 100 & 239 & 83 & $\mathrm{~N}$ & Asymptomatic \\
\hline 10 & $\mathrm{~F}$ & 10 & 13 & 24 & 80 & & 210 & $Y$ & Mild \\
\hline 11 & $\mathrm{~F}$ & 38 & 19 & 22.2 & & 201 & 63 & Y & Moderate \\
\hline 12 & $\mathrm{~F}$ & 25 & 14 & 22.3 & & 240 & 200 & Y & Mild \\
\hline 13 & $\mathrm{~F}$ & 66 & & & & 278 & 600 & Y & Mild \\
\hline 14 & $\mathrm{~F}$ & 49 & 25 & 29 & & & & Y & Moderate \\
\hline 15 & $M$ & 20 & & & & & & N & Asymptomatic \\
\hline
\end{tabular}


Table III. Clinical and laboratory data of patients affected by C1-INH-HAE

\begin{tabular}{|c|c|c|c|c|c|c|c|}
\hline $\begin{array}{l}\text { C1-INH-HAE } \\
\text { Pt id }\end{array}$ & Gender & Age & C4 & $\begin{array}{l}\text { C1-INH } \\
\text { antigen }\end{array}$ & $\begin{array}{c}\text { C1-INH } \\
\text { function \% }\end{array}$ & $\begin{array}{c}\text { Symptoms } \\
(y / n)\end{array}$ & $\begin{array}{c}\text { Bygum } \\
\text { severity } \\
\text { score }\end{array}$ \\
\hline 1 & $M$ & 46 & 5 & 6.4 & 15 & Y & 6 \\
\hline 2 & $M$ & 29 & 2 & 6 & & Y & 7 \\
\hline 3 & $M$ & 43 & 6 & 8 & & $\mathrm{~N}$ & 0 \\
\hline 4 & $M$ & 39 & 5 & 6.5 & & Y & 2 \\
\hline 5 & $\mathrm{~F}$ & 16 & 2 & 5.6 & 30 & Y & 9 \\
\hline 6 & $M$ & 46 & 3 & 8 & 9 & $Y$ & 8 \\
\hline 7 & $\mathrm{~F}$ & 52 & 2 & 5.6 & 22 & Y & 8 \\
\hline 8 & $\mathrm{~F}$ & 81 & 7 & 5.6 & & Y & 4 \\
\hline 9 & $\mathrm{~F}$ & 66 & 8 & 7.2 & 40 & Y & 6 \\
\hline 10 & $\mathrm{~F}$ & 40 & 1 & 4.8 & & Y & 7 \\
\hline 11 & $\mathrm{~F}$ & 68 & 1 & 4.8 & 20 & Y & 9 \\
\hline 12 & $\mathrm{~F}$ & 54 & 3 & 7 & 33 & Y & 6 \\
\hline 13 & $\mathrm{~F}$ & 33 & 5 & 6.5 & 27 & Y & 8 \\
\hline 14 & $\mathrm{~F}$ & 51 & 1 & 7 & 27 & Y & 5 \\
\hline 15 & $M$ & 45 & 6 & 11.9 & & Y & 6 \\
\hline 16 & $M$ & 31 & 9 & 11 & & Y & 9 \\
\hline 17 & $\mathrm{~F}$ & 74 & 3 & 9 & & Y & 8 \\
\hline 18 & $\mathrm{~F}$ & 42 & 1 & 2 & & Y & 4 \\
\hline 19 & $\mathrm{~F}$ & 78 & 8 & 10 & & $Y$ & 4 \\
\hline
\end{tabular}

Normal ranges as follows: C1-INH antigen (Ag) 21-39 mg/dl; C1-INH function (Fn) 70-130\%; serum C4 antigen 10-40 mg/dl.

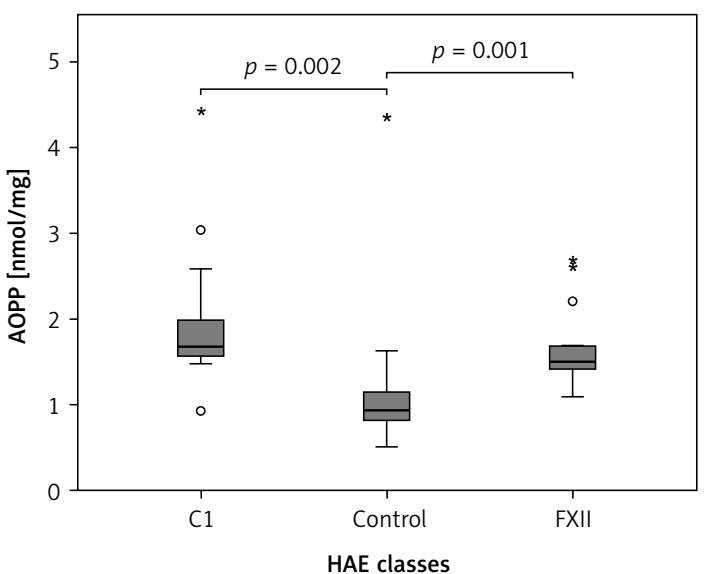

Figure 1. The AOPP ( $\mathrm{nmol} / \mathrm{mg}$ protein) concentration among HAE patients and healthy controls. Box plot illustrates median (IQR) AOPP levels in groups of individuals of different HAE classes (C1, FXII) and control group. The Mann-Whitney $U$ test was used for paired comparisons; $p$-values and medians are indicated in the figure

controls. Post hoc analysis of AGE levels (Figure 2) showed that the value in the FXII group (141.48 (89.59) AU/g) was lower and significantly different

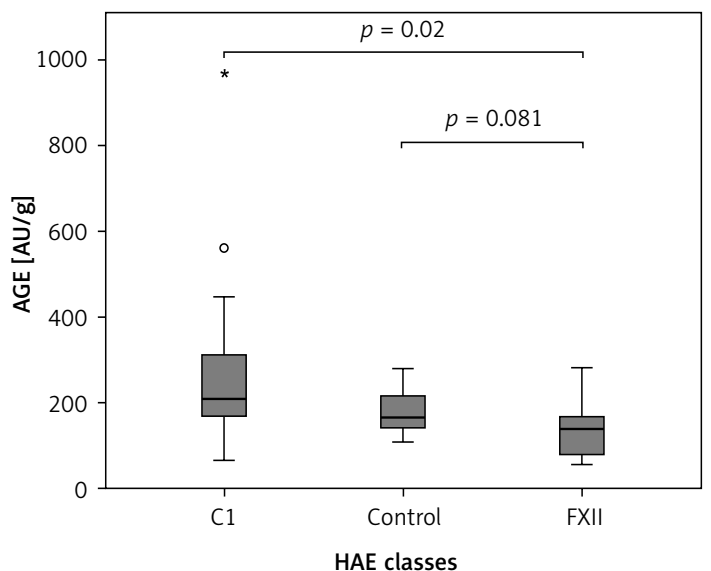

Figure 2. The AGE (AU/g protein) concentration among HAE patients and healthy controls. Box plot illustrates median (IQR) AGE levels in groups of individuals of different HAE classes (C1, FXII) and control group. The Bonferroni post hoc test was used for paired comparisons; $p$-values and medians are indicated in the figure

versus the C1-INH-HAE group (211.58 (151.05) AU/g; $p=0.02)$ and comparable with the control group (167.02 (78.76) AU/g; $p=0.081$ ). 


\section{Discussion}

There is increasing interest in identification of specific biomarkers, defined by the National Institutes of Health as "a characteristic that is objectively measured and evaluated as an indicator of normal biological processes, pathogenic processes, or pharmacological responses to a therapeutic intervention". In particular, biomarkers of oxidative stress can be classified as molecules (DNA, lipids, proteins or carbohydrates) modified by interactions with ROS in the microenvironment; and molecules of the antioxidant system that change in response to increased redox stress. The AGEs and AOPPs can serve as densitometric markers of oxidative stress and inflammation in several diseases and their complications [10,11, 13, 15, 23-25]. In fact, modified proteins may be, more efficiently than other biomarkers, employed to monitor disease progression and outcome, since proteins are, in general, key molecules that play the ultimate role in various structural and functional aspects of living organisms, and their activity and function are strictly dependent on structure, conformation and folding pattern. Thus, modification of conformation/structure of the polypeptide chain in conditions of oxidative stress/inflammation can lead to dysfunction/function, loss of proteins, and inhibition of their degradation (and, consequently, their accumulation) and also has a wide range of downstream functional consequences, causing subsequent cellular dysfunction, tissue damage, and disease onset/progression. Furthermore, as the techniques used to measure AGEs and AOPPs are simple, fast, and inexpensive, they may be applicable in daily routine laboratory practice for assessing and monitoring oxidative stress in critically ill and several other types of patients. These biomarkers, as well as other modified proteins, also have the further advantages of relative stability and consequent higher blood concentrations [14].

Our data indicate that both C1-INH-HAE and FXII-HAE are associated with a state of increased oxidative stress, as shown by the increased circulating levels of AOPPs and, in C1-INH-HAE only, of AGEs. Bradykinin generation and signaling appear to be important in HAE as well as angioedema due to ACE inhibitors [26], but they contribute to several other diseases, in particular anaphylaxis and mast-cell mediated allergic reactions [27, 28], as well as systemic mastocytosis [29], which is characterized by increased circulating AOPP levels.

On the other hand, serum AOPP levels were higher in C1-INH-HAE patients than in FXII-HAE patients, and AGE serum levels were higher only in C1-INH-HAE patients than in controls.

It has been proposed that FXII-HAE may be potentially more closely linked with BK and B2 re- ceptors, and C1-INH-HAE with desArg9-BK and B1 receptors [8, 30, 31].

In fact, both the B1 and B2 receptors mediate vasodilation and permeability increase and, through their binding to the receptors, there is activation of G-proteins and downstream effectors including eNOS, PLA2 and PLC- $\beta 1$ [17]. In general, the protective role of $B 2 \mathrm{R}$ in oxidative stress-mediated disorders of the kidney and heart is recognized [32], through eNOS induction and tonic NO production [33].

Increased eNOS levels in attack-free periods have been observed in C1-INH-HAE patients [34], although with evidence of an underlying endothelial dysfunction $[35,36]$. In fact, bradykinin receptors may have dual beneficial and deleterious effects in vascular and inflammation physiopathology $[17,37]$. Besides the B2R-like pathways, $B 1 R$ leads to prolonged signaling and to stimulation of iNOS, which generates a much higher and prolonged output of NO with the potential to promote inflammatory responses [38, 39]. High levels of NO can react with superoxide anion to generate peroxynitrites and increase oxidative stress in mice [40].

Activation of B1R increases the oxidative stress through the activation of NADPH oxidase, resulting in increased superoxide anions in human cells and rat models [41, 42].

Our data might be linked to differences in bradykinin receptor signaling, resulting in a different pattern of the measured oxidative stress markers among HAE subgroups.

The BK formation may occur independently from factor XII and kallikrein, relying on the lectin pathway of the complement system and activation of MBL-associated serine protease (MASPS), which are also activated upon oxidative stress [43]. The potential impact of the measured markers of oxidative stress in HAE attacks through MASPs deserves further investigations. C1-INHHAE is associated with dysregulation of complement, coagulation, and contact cascades [44], and high levels of procoagulant and fibrinolytic activity have been demonstrated in patients during acute attacks and remissions $[45,46]$. Thus, the different behavior observed between C1-INH-HAE patients and FXII-HAE patients may be related to a different imbalance in the coagulation, contact and kinin pathways [47, 48]. The oxidation of fibrinogen plays a key role in the formation of AOPPs, which, in turn, may promote functional alterations in fibrinogen, increasing its procoagulant activity or modifying its direct effects on vascular tone [49, 50]. Furthermore, blood levels of AGEs are a biomarker known to be intimately involved in the pathophysiology of cardiovascular disease and appear to be directly associated 
with the onset of thrombotic risk; for example, we observed increased AGE serum levels in patients affected by essential thrombocythemia and who had experienced thrombotic events [15, 51].

The apparent potential thromboembolic risk in patients with C1-INH-HAE, with activation of fibrinolytic activity and coagulation as well as high levels of D-dimer, has not been confirmed by clinical observations and needs to be addressed with further studies [18, 45, 46].

Finally, FXII-HAE was previously named "estrogen-dependent" HAE; thus an explanation for the difference between the two HAE subgroups could be found in a different capability of estrogen to modulate vascular reactivity and inflammation, coagulation and platelet aggregation $[31,52,53]$.

To our knowledge, this is the first study to investigate the role of oxidative stress in $\mathrm{HAE}$, highlighting additional underlying mechanisms involved in this disease. Further studies are in progress to better characterize the effects of oxidative stress on different systems involved in $\mathrm{HAE}$ pathophysiology.

\section{Acknowledgments}

The authors thank the patients and their relatives for their participation in this study. This study was performed with institutional funding of the University of Messina and University of Cagliari.

\section{Conflict of interest}

The authors declare no conflict of interest.

\section{References}

1. Cicardi M, Aberer W, Banerji A. et al. Classification, diagnosis, and approach to treatment for angioedema: consensus report from the Hereditary Angioedema International Working Group. Allergy 2014; 69: 602-16.

2. Bork K, Wulff K, Witzke G, Hardt J. Hereditary angioedema with normal C1-INH with versus without specific F12 gene mutations. Allergy 2015; 70: 1004-12.

3. Firinu D, Barca MP, Serusi L, et al. Switch to icatibant in a patient affected by hereditary angioedema with high disease activity: a case report. Int I Immunopathol Pharmacol 2012; 25: 269-73.

4. Nussberger J, Cugno M, Amstutz C, Cicardi M, Pellacani A, Agostoni A. Plasma bradykinin in angio-oedema. Lancet 1998; 351: 1693-7.

5. Cugno M, Nussberger J, Cicardi M, Agostoni A. Bradykinin and the pathophysiology of angioedema. Int Immunopharmacol 2003; 3: 311-7.

6. de Maat S, Björkqvist J, Suffritti C, et al. Plasmin is a natural trigger for bradykinin production in hereditary angioedema with factor XII mutations. J Allergy Clin Immunol 2016; 138: 1414-23.e9.

7. Dewald G, Bork K. Missense mutations in the coagulation factor XII (Hageman factor) gene in hereditary angioedema with normal C1 inhibitor. Biochem Biophys Res Commun 2006; 343: 1286-9.
8. Charignon D, Ghannam A, Defendi F, et al. Hereditary angioedema with F12 mutation: factors modifying the clinical phenotype. Allergy 2014; 69: 1659-65.

9. Holguin F, Fitzpatrick A. Obesity, asthma, and oxidative stress. J Appl Physiol (1985) 2010; 108: 754-9.

10. Kalousova M, Zima T, Tesar V, Dusilova-Sulkova S, Skrha J. Advanced glycoxidation end products in chronic diseases-clinical chemistry and genetic background. Mutat Res 2005; 579: 37-46.

11. Piwowar A. [Advanced oxidation protein products. Part I. Mechanism of the formation, characteristics and property]. Pol Merkur Lekarski 2010; 28: 166-9.

12. Gangemi S, Allegra A, Aguennouz M, et al. Relationship between advanced oxidation protein products, advanced glycation end products, and S-nitrosylated proteins with biological risk and MDR-1 polymorphisms in patients affected by B-chronic lymphocytic leukemia. Cancer Investig 2012; 30: 20-6.

13. Gangemi S, Allegra A, Alonci A, et al. Increase of novel biomarkers for oxidative stress in patients with plasma cell disorders and in multiple myeloma patients with bone lesions. Inflamm Res 2012; 61: 1063-7.

14. Miraglia N, Assennato G, Clonfero E, Fustinoni S, Sannolo N. [Biologically effective dose biomarkers]. G Ital Med Lav Ergon 2004; 26: 298-301.

15. Musolino C, Allegra A, Saija A, et al. Changes in advanced oxidation protein products, advanced glycation end products, and s-nitrosylated proteins, in patients affected by polycythemia vera and essential thrombocythemia. Clin Biochem 2012; 45: 1439-43.

16. Kaplan AP, Joseph K, Silverberg M. Pathways for bradykinin formation and inflammatory disease. J Allergy Clin Immunol 2002; 109: 195-209.

17. Couture R, Blaes N, Girolami JP. Kinin receptors in vascular biology and pathology. Curr Vasc Pharmacol 2014; 12: 223-48.

18. Firinu D, Bafunno V, Vecchione G, et al. Characterization of patients with angioedema without wheals: the importance of F12 gene screening. Clin Immunol 2015; 157: 239-48.

19. Bafunno V, Bova M, Loffredo S, et al. Mutational spectrum of the $\mathrm{c} 1$ inhibitor gene in a cohort of Italian patients with hereditary angioedema: description of nine novel mutations. Ann Hum Genet 2014; 78: 73-82.

20. Firinu D, Colomba P, Manconi PE, et al. Identification of a novel and recurrent mutation in the SERPING1 gene in patients with hereditary angioedema. Clin Immunol 2013; 147: 129-32.

21. Gomez-Traseira C, Lopez-Lera A, Drouet C, et al. Hereditary angioedema caused by the p.Thr309Lys mutation in the F12 gene: a multifactorial disease. J Allergy Clin Immunol 2013; 132: 986-9.e1-5.

22. Bygum A, Fagerberg CR, Ponard D, Monnier N, Lunardi J, Drouet C. Mutational spectrum and phenotypes in Danish families with hereditary angioedema because of C1 inhibitor deficiency. Allergy 2011; 66: 76-84.

23. Di Lorenzo G, Minciullo PL, Leto-Barone MS, et al. Differences in the behavior of advanced glycation end products and advanced oxidation protein products in patients with allergic rhinitis. J Investig Allergol Clin Immunol 2013; 23: 101-6.

24. Bowler RP, Crapo JD. Oxidative stress in allergic respiratory diseases. J Allergy Clin Immunol 2002; 110: 349-56.

25. Spatari G, Saitta S, Cimino F, et al. Increased serum levels of advanced oxidation protein products and glycation end products in subjects exposed to low-dose benzene. Int J Hyg Environ Health 2012; 215: 389-92. 
26. Faisant C, Armengol G, Bouillet, et al. Angioedema triggered by medication blocking the renin/angiotensin system: retrospective study using the French National Pharmacovigilance Database. J Clin Immunol 2016; 36: 95-102.

27. Patella V, Incorvaia C, Minciullo PL, et al. Oxidative stress markers in patients with hymenoptera venom allergy. Allergy Asthma Proc 2015; 36: 9-13.

28. Sala-Cunill A, Bjorkqvist J, Senter R, et al. Plasma contact system activation drives anaphylaxis in severe mast cell-mediated allergic reactions. J Allergy Clin Immunol 2015; 135: 1031-43e1036.

29. Gangemi S, Minciullo PL, Magliacane D, et al. Oxidative stress markers are increased in patients with mastocytosis. Allergy 2015; 70: 436-42.

30. Bossi F, Fischetti F, Regoli D, et al. Novel pathogenic mechanism and therapeutic approaches to angioedema associated with C1 inhibitor deficiency. J Allergy Clin Immunol 2009; 124: 1303-10e1304.

31. Wu H, Roks AJ, Leijten FP, et al. Genetic variation and gender determine bradykinin type 1 receptor responses in human tissue: implications for the ACE-inhibitor-induced effects in patients with coronary artery disease. Clin Sci (Lond) 2014; 126: 441-9.

32. Chao J, Li HJ, Yao YY, et al. Kinin infusion prevents renal inflammation, apoptosis, and fibrosis via inhibition of oxidative stress and mitogen-activated protein kinase activity. Hypertension 2007; 49: 490-7.

33. Kayashima Y, Smithies O, Kakoki M. The kallikrein-kinin system and oxidative stress. Curr Opin Nephrol Hypertens 2012; 21: 92-6.

34. Demirturk M, Gelincik A, Cinar S, et al. Increased eNOS levels in hereditary angioedema. Int Immunopharmacol 2014; 20: 264-8.

35. Demirturk M, Polat N, Guz G, et al. There is an increased risk of atherosclerosis in hereditary angioedema. Int Immunopharmacol 2012; 12: 212-6.

36. Czucz J, Schaffer G, Csuka D, et al. Endothelial cell function in patients with hereditary angioedema: elevated soluble E-selectin level during inter-attack periods. J Clin Immunol 2012; 32: 61-9.

37. Leeb-Lundberg LM, Marceau F, Muller-Esterl W, Pettibone DJ, Zuraw BL. International union of pharmacology. $X L V$. Classification of the kinin receptor family: from molecular mechanisms to pathophysiological consequences. Pharmacol Rev 2005; 57: 27-77.

38. Kuhr F, Lowry J, Zhang Y, Brovkovych V, Skidgel RA. Differential regulation of inducible and endothelial nitric oxide synthase by kinin B1 and B2 receptors. Neuropeptides 2010; 44: 145-54.

39. Tocchetti CG, Molinaro M, Angelone T, et al. Nitrosoredox balance and modulation of basal myocardial function: an update from the Italian Society of Cardiovascular Research (SIRC). Curr Drug Targets 2015; 16: 895-903.

40. Kuhlencordt PJ, Chen J, Han F, Astern J, Huang PL. Genetic deficiency of inducible nitric oxide synthase reduces atherosclerosis and lowers plasma lipid peroxides in apolipoprotein E-knockout mice. Circulation 2001; 103: 3099-104.

41. Talbot S, Lin JC, Lahjouji K, et al. Cigarette smoke-induced kinin B1 receptor promotes NADPH oxidase activity in cultured human alveolar epithelial cells. Peptides 2011; 32: 1447-56.

42. Dias JP, Talbot S, Senecal J, Carayon P, Couture R. Kinin $B 1$ receptor enhances the oxidative stress in a rat mod el of insulin resistance: outcome in hypertension, allo- dynia and metabolic complications. PLoS One 2010; 5: e12622.

43. Dobo J, Major B, Kekesi KA, et al. Cleavage of kininogen and subsequent bradykinin release by the complement component: mannose-binding lectin-associated serine protease (MASP)-1. PLoS One 2011; 6: e20036.

44. Kaplan AP, Joseph K. Pathogenic mechanisms of bradykinin mediated diseases: dysregulation of an innate inflammatory pathway. Adv Immunol 2014; 121: 41-89.

45. van Geffen M, Cugno M, Lap P, Loof A, Cicardi M, van Heerde W. Alterations of coagulation and fibrinolysis in patients with angioedema due to C1-inhibitor deficiency. Clin Exp Immunol 2012; 167: 472-8.

46. Reshef A, Zanichelli A, Longhurst H, Relan A, Hack CE. Elevated $\mathrm{D}$-dimers in attacks of hereditary angioedema are not associated with increased thrombotic risk. Allergy 2015; 70: 506-13.

47. Bjorkqvist J, de Maat S, Lewandrowski U, et al. Defective glycosylation of coagulation factor XII underlies hereditary angioedema type III. J Clin Invest 2015; 125 . 3132-46.

48. Kajdacsi E, Jani PK, Csuka D, et al. Novel vasoregulatory aspects of hereditary angioedema: the role of arginine vasopressin, adrenomedullin and endothelin-1. J Clin Immunol 2016; 36: 160-70.

49. Bas M, Kirchhartz N, Hochfeld J, et al. Potential role of vasomotor effects of fibrinogen in bradykinin-induced angioedema. J Allergy Clin Immunol 2008; 121: 969$75 e 962$.

50. Torbitz VD, Bochi GV, de Carvalho JA, de Almeida Vaucher R, da Silva JE, Moresco RN. In vitro oxidation of fibrinogen promotes functional alterations and formation of advanced oxidation protein products, an inflammation mediator. Inflammation 2015; 38: 1201-6.

51. Ahearn J, Shields KJ, Liu CC, Manzi S. Cardiovascular disease biomarkers across autoimmune diseases. Clin Immunol 2015; 161: 59-63.

52. Roy-O'Reilly M, McCullough LD. Sex differences in stroke: the contribution of coagulation. Exp Neurol 2014; 259 16-27.

53. Xing D, Nozell S, Chen YF, Hage F, Oparil S. Estrogen and mechanisms of vascular protection. Arterioscler Thromb Vasc Biol 2009; 29: 289-95. 